\title{
Prehospital advanced cardiac life support with a smartphone-based direct medical oversight in a metropolitan city: a before-after population-based study
}

\author{
Jae Jin Hong, Seong Jung Kim, Yongjin Park \\ Department of Emergency Medicine, School of Medicine, Chosun University, Gwangju, Korea
}

Received October 16, 2020

Revised October 21, 2020

Accepted October 26, 2020

Corresponding author

Yongjin Park

Department of Emergency

Medicine, School of Medicine,

Chosun University, 365 Pilmun-

daero, Dong-gu, Gwangju 61452,

Korea

Tel: +82-62-220-3285

Fax: +82-62-224-3501

E-mail: eryongjin@chosun.ac.kr ORCID:

https://orcid.org/0000-0001-8033-1704

\begin{abstract}
This study aimed to determine whether advanced life support (ALS) under emergency physician's direct medical oversight through video call on smartphones was associated with improved out-of-hospital cardiac arrest (OHCA) outcomes on "Smart Advanced Life Support (SALS)" pilot project. This study was conducted with a "before-after" controlled trial. We divided the OHCA patients in a metropolitan city with a population of 1.5 million into two periods. The 'Before' phase was performed the basic life support (BLS group) in 2014, and the 'after' phase was performed the ALS using video calls on smartphones (SALS group) in 2015. The primary and secondary outcomes were survival to discharge and a good neurological outcome, respectively. We conducted propensity score matching to equalize potential prognostic factors in both groups. 235 OHCA patients were enrolled in the BLS group, 198 patients in the SALS group. The outcomes were better in the SALS group than in the BLS group for survival to discharge and good neurological outcome, respectively. The adjusted ORs of SALS group compared to those BLS group $1.33(95 \% \mathrm{Cl} 1.00-1.77)$ for survival to discharge and 1.73 (95\% Cl 1.19-2.53) for good neurologic outcome. An emergency medical system intervention using the SALS protocol was associated with a significant increase in prehospital ROSC and an improved survival and neurologic outcome after OHCA.
\end{abstract}

Keywords: Out-of-hospital cardiac arrest; Smartphone; Advanced cardiac life support; Emergency medical system

\section{INTRODUCTION}

In 2014, there were about 30,000 cases of out-of-hospital cardiac arrest (OHCA) in Republic of Korea, and 56.7 cases per 100,000 people. This is an increase of more than $10 \%$ compared to 50.5 per 100,000 people in 2006 , and is increasing every year. However, despite the efforts of many medical policy officers, paramedics, and doctors, the survival outcomes after cardiac arrest remained at $4.8 \%$ in both 2013 and 2014, which is relatively poor compared to other countries [1-4]. Among them, it is seen that the faster the return of spontaneous circulation (ROSC) is the higher the chances of good neurological outcome and for this, it was considered to be more advantageous to make a pre-hospital 
ROSC. But given the procedure in Korea for OHCA, only basic life support (BLS) is given at the site within 5 minutes and then transported to the hospital so it is difficult to expect circulation recovery before arriving at a hospital.

A number of the study support that prehospital advanced life support (ALS) was not effective for out-of-hospital cardiac arrest (OHCA) patients [5-9]. The experience of the paramedics exposed to OHCA patients affects the treatment of cardiac arrest, but the actual exposure of the paramedics is rare and declining. Prehospital emergency medical direction (EMS) - physician presence was associated with improved survival outcomes of the patient, but the characteristics of the EMS operating in each country are different, and there are places where the operation is not possible in reality [1012].

However, recently developed video communication technologies have created opportunities to make various attempts in the medical field. A "Smart Advanced Life Support" (SALS) pilot project was introduced to some areas on a trial basis; where in the event of a cardiac arrest, the nearest two units of emergency medical services (EMS) are dispatched, and through the visual directions of an emergency physician, the paramedics will use the manual defibrillator, administer drugs, and perform advanced life support.

The objective of this study was to determine whether SALS under physician's direct medical oversight through video call on smartphones was associated with improved OHCA outcomes in a metropolitan city.

\section{MATERIALS AND METHODS}

\section{Design}

This study was conducted with a "before-after" controlled trial. We divided the OHCA patients in the study area into two periods: before and after. The 'before' phase performed the same BLS for 12 months (January 2014 to December 2014), and the 'after' phase performed the video medical guidance for a total of 12 months (January 2015 to December 2015).

In both periods, the EMT filled out the patient's ambulance run sheet after dispatched to the cardiac arrest scene, Ambulance run sheets are electronically stored in each provincial EMS headquarters, managed by the National Fire Agency (NFA). In after phase, the EMT additionally filled out the 'SALS chart', directing physicians made the 'Oversight physician report'. Trained reviewers visited the hospital where the patient was transferred, reviewed medical record to complete the outcomes according to the Utstein style [13]. These data are electronically stored in national emergency medical center (NEMC). Finally, the NEMC secured the sheet with the cooperation of the NFA and constructed the SALS database. Physicians responsible for database quality control in this study performed a structured, explicit data review. This study was practically impossible to obtain the informed consent of the subjects, so a written consent was waivered. This study was carried after the Institutional Review Board approval from the Research Ethics Committee of the Chosun University Hospital (No. 2015-12-009).

\section{Setting}

The setting was the metropolitan city of the Republic of Korea, with a population of approximately 1.5 million people in $501 \mathrm{~km}^{2}$, consisting mostly of urban area. There are 30 ambulances, 270 paramedics and 24 ambulance stations. Korean EMS has recently established a centrally based, two-tiered system for OHCA patients, two or three EMT including at least one intermediate EMT (EMT-I) or nurse per ambulance were dispatched. Ambulance crew can provide care that is comparable to the EMT-I level in the US, including intravenous fluids, endotracheal intubation or laryngeal mask airway insertion under direct medical oversight. But, they cannot use medications for ALS (e.g., epinephrine, amiodarone). This means that it is not enough time to provide ALS in the field, only BLS is being performed. One of the most important factors for ROSC is that high-quality BLS should be continuously performed for a reasonable period of time, and 10 minutes of on-site CPR is a very short time.

\section{Selection of study participants}

The study was performed on non-trauma cardiac arrest patients who were 18 years of age or older with cardiopulmonary resuscitation. Cardiac arrest patients due to trauma, poisoning, pregnancy, do not attempt resuscitation (DNAR), and patients CPRs which were put off due to definite death (for example decapitation, incineration, decomposition, rigor motis, or dependent cyanosis) were excluded from this study. Also, even if they qualified for the pilot project, if the patients' family did not agree on SALS pilot project 

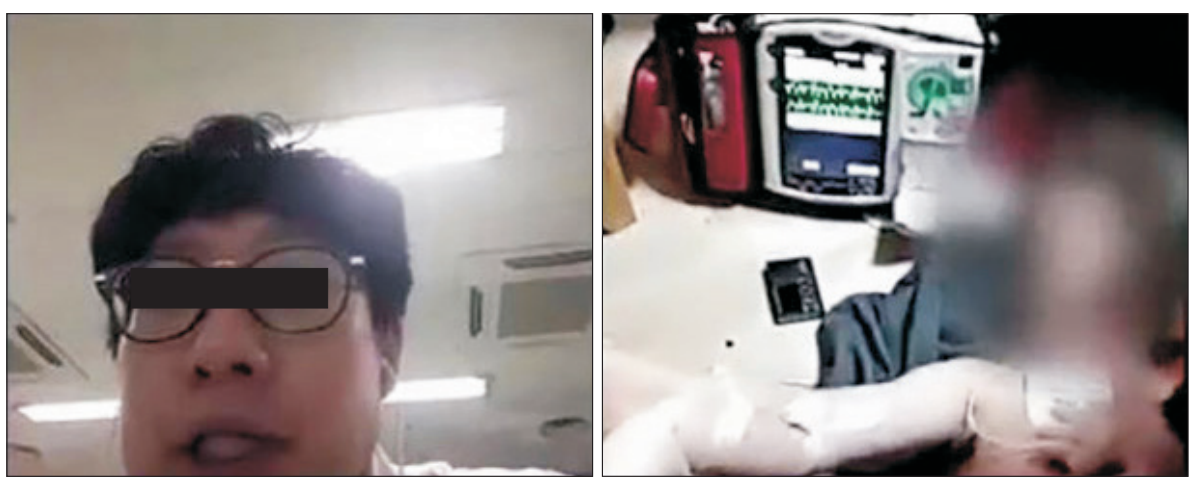

Fig. 1. Capture images during videophoneassisted advanced life support. The EMT leader takes the patient to the center of the screen and records the EMT's performance on whole screen. After 2 minutes of chest compression, EMT adjusts the angle of the camera so that the rhythm of the ECG can be monitored.

and wanted the patient transported to a hospital quickly, BLS was given as per standard procedure, and was excluded from the study.

\section{Intervention}

In the 'before' phase, EMTs dispatched to the field, perform a conventional BLS about 5 minutes and transfer to the nearest hospital. EMTs, which cannot declare death or stop CPR, can take medical directions from a physician via telephone when there is an apparent suspicion of death, such as when decapitation, rigor mortis, decomposition, and dependent lividity are observed.

In the 'after' phase, at the area implemented SALS pilot project, they were allowed to undergo further intravenous fluid, intravenous medications, advanced airway insertion (e.g., I-gel, endotracheal intubation) under physician's direct medical oversight through video call (Fig. 1).

\section{Outcome measure}

The first outcome measure is to measure the prehospital-spontaneous recovery rate of the hospital. The second outcome measure was to measure the survival rate and neurological recovery rate according to Utstein style [13]. Neurological recovery rates were measured at discharge. The recovery rate was measured using the cerebral performance category (CPC) score, and CPC 1 and 2 were defined as good neurological recovery [14].

\section{Statistical analysis}

Statistical analysis was performed using SPSS version 21.0 for Windows (SPSS Inc., Chicago, IL, USA). Nominal variables were expressed as counts and percentages of total numbers. Continuous variables were expressed using medi-

\section{Patients with out-of-hospital cardiac arrest assessed by EMS ( $\mathrm{N}=1,333)$}

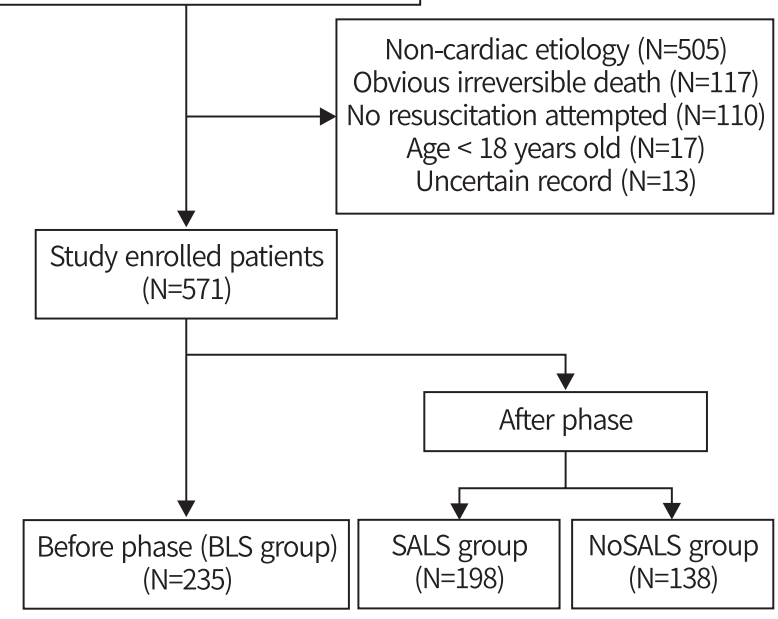

Fig. 2. Study flow. EMS: emergency medical service, CPR: cardiopulmonary resuscitation, SALS: smartphone video assisted advanced life support.

an and interquartile range (IQR).

Differences between BLS and SALS groups were compared using chi-square test of Fisher's exact test for nominal variables and Independent sample t-test for continuous variables. The statistical significance was judged to be the case when the $\mathrm{p}$ value was less than 0.05 .

We matched the propensity score by using logistic regression model to compare the effects of SALS vs. BLS on the outcomes of OHCA patients. Data with missing values were excluded from the collected data. The independent variables (covariates) being potential risk factor of sex, age, witnessed, bystander CPR, public place, shockable rhythm were included. We calculated propensity scores to a maximum of 10 decimal place. Patients received SALS were matched to the closest BLS group patient whose propensity score differed by less than $1 / 10-4$. 
Adjusted multivariable logistic regression analysis was used to examine the associations between SALS and outcome except for data with missing values. Associations are presented as odds ratios (ORs) with $95 \%$ confidence intervals (CI).

\section{RESULTS}

\section{Outcomes}

Among 1,333 EMS-assessed OHCA, 235 patients in before

Table 1. Baseline characteristics of the study patients in BLS and SALS groups

\begin{tabular}{|c|c|c|c|}
\hline Characteristics & BLS group $(N=235)$ & SALS group $(N=198)$ & $p$ value \\
\hline \multicolumn{4}{|l|}{ Patient \& environmental factor } \\
\hline Male sex - no. (\%) & $147(62.5)$ & $135(68.2)$ & $<0.001$ \\
\hline Age-year - median (IQR) & $70(56-80)$ & $71(56-79)$ & 0.48 \\
\hline Public place - no. (\%) & $40(17.3)$ & $35(17.6)$ & 0.55 \\
\hline Witnessed arrest - no. (\%) & $115(48.9)$ & $97(49.0)$ & 0.10 \\
\hline Bystander CPR - no. (\%) & $133(56.6)$ & $138(69.7)$ & $<0.001$ \\
\hline Initial cardiac rhythm - no. (\%) & & & $<0.001$ \\
\hline Ventricular fibrillation/tachycardia & $39(16.6)$ & $40(20.4)$ & \\
\hline Pulseless electrical activity & $43(18.4)$ & $33(16.7)$ & \\
\hline Asystole & $150(63.9)$ & $124(62.9)$ & \\
\hline Unknown & $3(1.3)$ & $1(0.1)$ & \\
\hline \multicolumn{4}{|l|}{ EMS factor } \\
\hline Defibrillation shock - no. (\%) & $58(24.7)$ & $63(31.8)$ & $<0.001$ \\
\hline EMS defibrillation success - no. (\%) & $30(56.4)$ & $25(47.5)$ & 0.004 \\
\hline Number of defibrillation attempts - no. (SD) & $2.23(1.72)$ & $3.44(2.49)$ & $<0.001$ \\
\hline Prehospital advanced airway - no. (\%) & & $189(95.5)$ & NA \\
\hline \multicolumn{4}{|l|}{ Prehospital drug administered - no. (\%) } \\
\hline Epinephrine - no. (\%) & & $136(69.0)$ & NA \\
\hline Amiodarone - no. (\%) & & $11(5.6)$ & NA \\
\hline Fluid bolus - no. (\%) & & $146(73.7)$ & NA \\
\hline \multicolumn{4}{|l|}{ Time interval-min } \\
\hline Response time interval (Call to EMS arrival on scene) - median (IQR) & $8.0(6.0-11.0)$ & $7.0(6.0-9.0)$ & $<0.001$ \\
\hline From arrival at scene to departure - median (IQR) & $9.0(6.0-13.0)$ & $27.0(21.0-33.0)$ & $<0.001$ \\
\hline From departure to arrival at hospital - median (IQR) & $6.0(4.0-10.0)$ & $6.0(4.0-9.0)$ & 0.005 \\
\hline Call to arrival at hospital - median (IQR) & $25.0(20.0-32.0)$ & $42.0(35.0-49.0)$ & $<0.001$ \\
\hline Call to EMS basic life support - median (IQR) & $9.0(7.0-12.0)$ & $9.0(7.0-12.0)$ & $<0.001$ \\
\hline From arrival at scene to EMS basic life support - median (IQR) & $1.0(0-2.0)$ & $2.0(1.0-3.0)$ & 0.077 \\
\hline From arrival at scene to first ROSC - median (IQR) & $29.0(18.0-46.0)$ & $22.0(14.0-37.0)$ & $<0.001$ \\
\hline From EMS basic life support to first ROSC - median (IQR) & $28.0(16.0-47.0)$ & $20.0(12.0-35.0)$ & 0.02 \\
\hline Call to first ROSC - median (IQR) & $38.0(26.0-55.0)$ & $30.0(21.0-45.0)$ & $<0.001$ \\
\hline From arrival at scene to first shock delivered - median (IQR) & $4.0(2.0-8.0)$ & $3.0(2.0-4.0)$ & $<0.001$ \\
\hline \multicolumn{4}{|l|}{ Post resuscitation care } \\
\hline $\mathrm{PCl}-$ no. $(\%)$ & $6(2.6)$ & $14(7.0)$ & $<0.001$ \\
\hline Hypothermia therapy - no. (\%) & $12(5.0)$ & $12(6.0)$ & 0.02 \\
\hline ECMO therapy - no. (\%) & $4(1.7)$ & $6(3.0)$ & $<0.001$ \\
\hline \multicolumn{4}{|l|}{ Outcome } \\
\hline Return of spontaneous circulation & $20(8.5)$ & $44(22.2)$ & $<0.001$ \\
\hline Admission to hospital & $52(22.1)$ & $37(18.6)$ & 0.008 \\
\hline Survival to hospital discharge & $16(6.8)$ & $20(10.1)$ & $<0.001$ \\
\hline Good neurologic recovery & $10(4.2)$ & $13(6.6)$ & $<0.001$ \\
\hline
\end{tabular}

IQR: interquartile range, CPR: cardiopulmonary resuscitation, EMS: emergency medical service, SD: standard deviation, NA: not applicable, ROSC: return of spontaneous circulation, $\mathrm{PCl}$ : percutaneous coronary intervention, ECMO: extracorporeal membrane oxygenation. 
Table 2. Survival and outcomes of patients in BLS and SALS groups

\begin{tabular}{lccccc}
\hline \multicolumn{1}{c}{ Outcome } & BLS group (N=235) & SALS group (N=198) & p value & OR (95\% Cl) & Adjusted OR (95\% Cl) \\
\hline Prehospital ROSC - no. (\%) & $20(8.5)$ & $44(22.2)$ & $<0.001$ & $3.08(2.57-3.68)$ & $4.04(3.24-5.03)$ \\
ED ROSC $^{\text {b }}$ no. (\%) & $63(26.8)$ & $16(8.0)$ & $<0.001$ & $0.24(0.20-0.29)$ & $0.22(0.18-0.27)$ \\
Total ROSC ${ }^{c}$ - no. (\%) & $83(35.3)$ & $60(30.3)$ & $<0.001$ & $0.79(0.70-0.90)$ & $0.73(0.63-0.85)$ \\
Admission to hospital - no. (\%) & $52(22.1)$ & $37(18.6)$ & 0.008 & $0.82(0.70-0.95)$ & $0.70(0.58-0.83)$ \\
Survival to discharge - no. (\%) & $16(6.8)$ & $20(10.1)$ & $<0.001$ & $1.48(1.20-1.84)$ & $1.23(0.96-1.68)$ \\
Good neurologic recovery - no. (\%) & $10(4.2)$ & $13(6.6)$ & $<0.001$ & $1.69(1.29-2.21)$ & $1.39(1.00-1.92)$ \\
\hline
\end{tabular}

OR: odds ratio, Cl: confidence interval, ROSC: return of spontaneous circulation, ED: emergency department. ${ }^{2}$ The analysis are adjusted for sex, age, place, witness, bystander CPR, initial shockable rhythm, response time interval (call to EMS arrival on scene), ${ }^{b} E D$ ROSC is ROSC, documented initially in emergency department without prehospital ROSC, ${ }^{\circ}$ Total ROSC corresponds to obtaining prehospital ROSC or ED ROSC.

phase (BLS group), 336 patients in after phase were included in the final analysis (Fig. 2). In after phase, 198 patients were performed SALS (SALS group), and 138 patients were not performed SALS and were transported to a hospital (NoSALS group).

Table 1 provides patient characteristics, EMS factor, time interval, post resuscitation care, outcome for the overall group. In SALS group, $69.7 \%$ of the bystander provided CPR for OHCA patients, whereas $56.6 \%$ of the bystander provided CPR in BLS group. A number of patients with shockable rhythm were more frequent in SALS group than in BLS group ( $20.4 \%$ vs. $16.6 \%$; $\mathrm{p}<0.001)$, whereas the success rate of the defibrillation by EMS provider were lower in SALS group than in BLS group ( $47.5 \%$ vs. $56.4 \%$; $\mathrm{p}=0.004$ ).

The EMS response time and transport time intervals in both groups did not show a difference. As ALS is implemented in the scene, from arrival at scene to departure time interval increased from 9.0 (median, 4.0-10.0) $\mathrm{min}$ to 27.0 (median, 21.0-33.0) $\min (\mathrm{p}<0.001)$. On the other hand, EMS arrival to first ROSC time interval 22.0 (median, 14.0-37.0) $\mathrm{min}$ in SALS group were shorter than in BLS group 29.0 (median, 18.0-46.0) $\mathrm{min}(\mathrm{p}<0.001)$. Prehospital ROSC rate in SALS group was higher than in BLS group (442 [22.2\%] vs. 200 [8.5\%]; p<0.001), respectively. In SALS group, 20 (10.1\%) survived to hospital discharge, as compared to $16(6.8 \%)$ in BLS group $(p<0.001)$. Rates of survival with favorable neurologic status were 13 (6.6\%) in SALS group, 10 (4.2\%) in BLS group $(\mathrm{p}<0.001)$, respectively.

\section{Logistic regression analysis}

Table 2 presents the multivariable logistic regression analysis on the outcomes for SALS group compared with BLS group. Perfoming SALS was associated with an increased likelihood of prehospital ROSC in analysis (22.2 vs. 8.5; adjusted odd ratio 4.04; $\mathrm{p}<0.001)$, survival to discharge (10.1 vs. 6.8; adjusted odd ratio $1.23 ; \mathrm{p}<0.001)$, good neurologic recovery (6.6 vs. 4.2; adjusted odd ratio 1.39; $\mathrm{p}<0.001$ ).

\section{Propensity score matching analysis}

We matched 304 patients on the propensity score for each of BLS and SALS groups. Both propensity-matched patients were well matched. Baseline characteristics comparing the propensity-matched BLS and SALS receiving patients are shown in Table 3. Patients received SALS was associated with increased odd of prehospital ROSC (odd ratio 3.60; 95\% confidence interval 2.83 to 4.58 ; $\mathrm{p}<0.001$ ), survival to discharge (odd ratio 1.33; 95\% confidence interval 1.00 to 1.77; $\mathrm{p}=0.05$ ), good neurologic recovery (odd ratio 1.73; $95 \%$ confidence interval 1.19 to $2.53 ; \mathrm{p}=0.004$ )(Table 4).

\section{DISCUSSION}

This study is the first attempt to clarify that ACLS performed by visual direct medical direction using smartphone was effective for the ROSC and neurological recovery of OHCA patients. It is also an unusual result that showed improvement in resuscitation rate and neurological recovery rate by implementing ALS for OHCA patients. Although the effect of prehospital ALS in OHCA has been questioned recently, the Spanish OHCA registry reported the higher rate of survival with favorable neurologic outcome of physician treated OHCA patients compared to paramedic based EMS legions [15]. And this study showed that recent developments in smartphone technology may be integrated with ALS.

Recently, the development of information and communication technology has made various attempts in the field 
Table 3. Selected characteristics according to SALS in propensity-matched patients

\begin{tabular}{|c|c|c|c|}
\hline Characteristics & BLS group $(N=152)$ & SALS group $(N=152)$ & $p$ value \\
\hline \multicolumn{4}{|l|}{ Patient \& environmental factor } \\
\hline Male sex - no. (\%) & $103(67.7)$ & $103(67.7)$ & 0.94 \\
\hline Age-year - median (IQR) & $59(50-70)$ & $60(51-73)$ & 0.28 \\
\hline Public place - no. (\%) & $24(15.8)$ & $26(17.1)$ & 0.35 \\
\hline Witnessed arrest - no. (\%) & $75(49.3)$ & $76(50.0)$ & 0.56 \\
\hline Bystander CPR - no. (\%) & $99(65.1)$ & $100(65.8)$ & 0.79 \\
\hline Initial cardiac rhythm - no. (\%) & & & 0.48 \\
\hline Ventricular fibrillation/tachycardia & $28(18.4)$ & $29(19.0)$ & \\
\hline Pulseless electrical activity & $28(18.4)$ & $26(17.1)$ & \\
\hline Asystole & $96(63.1)$ & $96(63.1)$ & \\
\hline Unknown & $0(0.0)$ & $1(0.7)$ & \\
\hline \multicolumn{4}{|l|}{ EMS factor } \\
\hline Defibrillation shock - no. (\%) & $40(26.3)$ & $49(32.2)$ & 0.001 \\
\hline EMS Defibrillation Success - no. (\%) & $22(55.0)$ & $24(49.0)$ & 0.05 \\
\hline Mean number of Defibrillation attempts - no. (SD) & $2.28(1.74)$ & $3.43(2.51)$ & $<0.001$ \\
\hline Prehospital advanced airway - no. (\%) & & $146(96.1)$ & \\
\hline \multicolumn{4}{|l|}{ Prehospital drug administered - no. (\%) } \\
\hline Epinephrine - no. (\%) & & $106(69.7)$ & \\
\hline Amiodarone - no. (\%) & & $8(5.3)$ & \\
\hline Fluid bolus - no. (\%) & & $114(75.0)$ & \\
\hline \multicolumn{4}{|l|}{ Time interval - min } \\
\hline Response time interval (call to EMS arrival on scene) - median (IQR) & $7.0(5.0-9.0)$ & $7.0(5.0-9.0)$ & 0.94 \\
\hline From arrival at scene to departure- median (IQR) & $11.0(7.0-15.0)$ & $23.0(17.0-30.0)$ & $<0.001$ \\
\hline From departure to arrival at hospital- median (IQR) & $6.0(4.0-9.0)$ & $7.0(4.0-10.0)$ & 0.004 \\
\hline Call to arrival at hospital - median (IQR) & $25.0(20.0-33.0)$ & $38.0(32.0-46.0)$ & $<0.001$ \\
\hline Call to EMS basic life support - median (IQR) & $8.0(6.0-11.0)$ & $9.0(7.0-11.0)$ & 0.79 \\
\hline From arrival at scene to EMS basic life support - median (IQR) & $1.0(0.0-2.0)$ & $2.0(1.0-2.0)$ & 0.15 \\
\hline From arrival at scene to first ROSC - median (IQR) & $21.0(10.0-41.0)$ & $22.0(13.0-38.0)$ & $<0.001$ \\
\hline From EMS basic life support to first ROSC - median (IQR) & $19.0(9.0-38.0)$ & $19.0(11.0-35.0)$ & 0.081 \\
\hline Call to first ROSC - median (IQR) & $28.0(17.0-50.0)$ & $29.0(20.0-44.0)$ & $<0.001$ \\
\hline From arrival at scene to first shock delivered - median (IQR) & $4.0(2.0-6.0)$ & $3.0(2.0-4.0)$ & $<0.001$ \\
\hline \multicolumn{4}{|l|}{ Post resuscitation care } \\
\hline $\mathrm{PCl}-$ no. $(\%)$ & $4(2.6)$ & $5(3.2)$ & 0.02 \\
\hline Hypothermia therapy - no. (\%) & $8(5.2)$ & $9(5.9)$ & 0.09 \\
\hline ECMO therapy - no. (\%) & $1(0.6)$ & $3(2.0)$ & $<0.001$ \\
\hline \multicolumn{4}{|l|}{ Outcome } \\
\hline Return of spontaneous circulation & $13(8.5)$ & $33(21.7)$ & $<0.001$ \\
\hline Admission to hospital & $32(21.0)$ & $28(18.4)$ & 0.02 \\
\hline Survival to hospital discharge & $11(7.2)$ & $14(9.2)$ & 0.06 \\
\hline Good neurologic recovery & $6(3.9)$ & $9(5.9)$ & 0.008 \\
\hline
\end{tabular}

IQR: interquartile range, CPR: cardiopulmonary resuscitation, EMS: emergency medical service, SD: standard deviation, NA: not applicable, ROSC: return of spontaneous circulation, $\mathrm{PCl}$ : percutaneous coronary intervention, ECMO: extracorporeal membrane oxygenation.

of EMS. The use of smartphones for medical oversight in cardiac arrest situations is very useful. Smartphones are lightweight, portable, easy to use, and cheaper than other medical devices. These advantages make it easier for EMTs and oversight doctors to share large amounts of information in emergency situations.

There are several reasons why this study could produce good result in a short period of time. First is the role of the 
Table 4. Odd ratios between two groups among propensity-matched patients

\begin{tabular}{|c|c|c|c|c|c|c|c|c|}
\hline \multirow{2}{*}{$\begin{array}{c}\text { Model } \\
\text { SALS (0) vs BLS }(1)(n=3,042)\end{array}$} & \multicolumn{2}{|c|}{ Prehospital ROSC } & \multicolumn{2}{|c|}{ Survival to admission } & \multicolumn{2}{|c|}{ Survival to discharge } & \multicolumn{2}{|c|}{ Good neurologic recovery } \\
\hline & OR $(95 \% \mathrm{Cl})$ & $p$ value & OR $(95 \% \mathrm{Cl})$ & $\mathrm{p}$ value & OR $(95 \% \mathrm{Cl})$ & $p$ value & $\mathrm{OR}(95 \% \mathrm{Cl})$ & $p$ value \\
\hline Unadjusted & $\begin{array}{c}2.96 \\
(2.39-3.68)\end{array}$ & $<0.001$ & $\begin{array}{c}0.81 \\
(0.68-0.97)\end{array}$ & 0.02 & $\begin{array}{c}1.29 \\
(1.00-1.67)\end{array}$ & 0.05 & $\begin{array}{c}1.54 \\
(1.12-2.13)\end{array}$ & 0.008 \\
\hline Adjusted for propensity & $\begin{array}{c}3.08 \\
(2.47-3.84)\end{array}$ & $<0.001$ & $\begin{array}{c}0.81 \\
(0.67-0.97)\end{array}$ & 0.02 & $\begin{array}{c}1.31 \\
(1.00-1.70)\end{array}$ & 0.05 & $\begin{array}{c}1.61 \\
(1.15-2.25)\end{array}$ & 0.006 \\
\hline $\begin{array}{l}\text { Adjusted for propensity and selected } \\
\text { variables }^{\mathrm{a}}\end{array}$ & $\begin{array}{c}3.60 \\
(2.83-4.58)\end{array}$ & $<0.001$ & $\begin{array}{c}0.77 \\
(0.63-0.93)\end{array}$ & 0.007 & $\begin{array}{c}1.33 \\
(1.00-1.77)\end{array}$ & 0.05 & $\begin{array}{c}1.73 \\
(1.19-2.53)\end{array}$ & 0.004 \\
\hline
\end{tabular}

ROSC: return of spontaneous circulation, OR: odds ratio, $\mathrm{Cl}$ : confidence interval. ${ }^{a}$ The analysis is adjusted for sex, age, place, witness, bystander $\mathrm{CPR}$, initial shockable rhythm, response time interval (call to EMS arrival on scene).

oversight physician to emphasize high-quality CPR. Until recently, limited studies indicate that exposure to OHCA for individual paramedics is rare, Dyson et al. reported that paramedics in Australia treat only $1.4 \mathrm{OHCA}$ patients per a year [16]. Such low exposure may impact on the paramedics' ability to perform resuscitation skills according to the guidelines, which is vital to patient survival [17].

Despite many controversies, it has been reported that physicians provide benefit to the patients who have cardiac arrest before the hospital [18]. Physician are able to carry out advanced procedures, such as airway management and epinephrine use, adhere to treatment according to guidelines, and have the latest knowledge. However, in this study, the physician did not respond to the field, so the latter may have affected the outcome of the treatment. Physician's advises and instructs on-site EMT leaders on team management and detailed ECG analysis, importance of BLS, and accurate ventilation. The presence of a physician with such experience and knowledge helps to improve the quality of care of the CPR team. In addition, EMT team leaders received continuous feedback could learn oversight during resuscitation, and grow into ACLS experts. In addition to the direct instruction of the physician, the Hawthorne effect may also have worked [19].

Second, the introduction of a strategy in each director can be assumed to have influenced performance [20-22]. Each month, we held a committee with oversight physicians, university hospital emergency attending doctors, fire office education administrators, dispatcher quality managers in each area. Monthly Results were shared, problems discovered and corrected. Based on the results of the committee meeting, re-training was conducted, transfer hospitals were selected, and hospitals were cooperated to provide effective interven- tion after cardiac arrest. This process provides an opportunity to objectively identify and rectify field weaknesses.

Lastly, it is also meaningful that each oversight doctor and EMT tried to communicate through social networking service (SNS). It is difficult for EMTs and oversight doctors to make contact with video or voice only in a cardiac arrest situation because it is much more office-friendly. Personal exchange among people increases intimacy. This affects feedback and retraining effects. Communication channels between hospitals and paramedics have indirectly positive effects for teamwork.

As a result of this intervention, pre-hospital ROSC increased in the SALS group, but survival hospitalization decreased further. On the other hand, survival rate and neurological recovery rate were found to be higher in the SALS group. Time to ROSC is a significant prognostic factor for the survival rate and neurological recovery rate of comatose OHCA patients [23,24]. The ROSC of the BLS group has been performed mostly in hospitals, but the Time to ROSC is longer. On the other hand, the ROSC of the SALS group was mostly performed in the field and the Time to ROSC was shorter. The prognosis of OHCA patients with rearrest was poor [25]. The hospital admission rate of SALS group was further reduced due to the inability to carry out critical interventions during transport, rearrest occurring after arrival at the hospital. Nonetheless, the decline in time to ROSC seems to increase survival rates and neurological recovery rates.

\section{Limitations}

This study has various limitations. First, it is a controlled before-after study, not planned RCT. In fact, the outcome of cardiac arrest in Korea is improving every year. RCT is 
needed to reflect the local demographic, social and regional characteristics. In Korea, RCT for cardiac arrest patients is ethically problematic and various legal aspects are needed. Also, due to the nature of this pilot project conducted by the government, it was not possible to determine patients who would randomly perform SALS. However, according to the results of cardiac arrest in Korea, the rate of survival discharge from 2006 to 2016 increased by an average of $0.54 \%$ from $2.3 \%$ to $7.6 \%$, and the neurological recovery rate increased by $0.36 \%$ from $0.6 \%$ to $4.2 \%$ each year. Second, approximately $40 \%$ of patients were excluded from the study due to the rejection of the family. This can lead to another selection bias, which can lead to confusion in a variety of other variables. However, we have no doubt about this result. To solve this problem, our results were statistically corrected using the propensity score matching method. Third, there were various changes like video medical direction, change to ACLS, increase of on-site time, drug administration, localization model, double tier dispatch, Hawthorne effect, Use of SNS, and training for EMTs, but we could not measure the effects of each of them. However, since pre-hospital ALS and direct medical guidance for OHCA patients are intertwined, it is difficult to measure the parameters separately. Also, the part of subjective evaluation involvement is also complex. The authors considered these changes to be the basic prerequisites for video medical direction and ALS. Of course, further study is needed to analyze the effect of each variable.

\section{ACKNOWLEDGMENTS}

This study was supported by research fund from Chosun University Hospital, 2018.

\section{CONFLICT OF INTEREST}

No potential conflict of interest relevant to this article was reported.

\section{REFERENCES}

1. Yang HJ, Kim GW, Kim H, Cho JS, Rho TH, Yoon HD, et al. Epidemiology and outcomes in out-of-hospital cardiac arrest: a report from the NEDIS-based cardiac arrest registry in
Korea. J Korean Med Sci 2015;30:95-103.

2. Ahn KO, Shin SD, Suh GJ, Cha WC, Song KJ, Kim SJ, et al. Epidemiology and outcomes from non-traumatic out-of-hospital cardiac arrest in Korea: a nationwide observational study. Resuscitation 2010;81:974-81.

3. Berdowski J, Berg RA, Tijssen JG, Koster RW. Global incidences of out-of-hospital cardiac arrest and survival rates: Systematic review of 67 prospective studies. Resuscitation 2010;81:1479-87.

4. Ma MHM, Ong ME, Shin SD, Siddiqui FJ, Tanaka H, Nishiuchi T, et al. The Pan Asian Resuscitation Outcomes Study (PAROS): characteristics of patients with out-of-hospital cardiac arrest across 7 countries in Asia. Circulation 2014;130:A69.

5. Sanghavi P, Jena AB, Newhouse JP, Zaslavsky AM. Outcomes after out-of-hospital cardiac arrest treated by basic vs advanced life support. JAMA Intern Med 2015;175:196-204.

6. von Vopelius-Feldt J, Brandling J, Benger J. Systematic review of the effectiveness of prehospital critical care following out-of-hospital cardiac arrest. Resuscitation 2017;114:40-6.

7. Stiell IG, Wells GA, Field B, Spaite DW, Nesbitt LP, De Maio VJ, et al. Advanced cardiac life support in out-of-hospital cardiac arrest. N Engl J Med 2004;351:647-56.

8. Sanghavi P, Jena AB, Newhouse JP, Zaslavsky AM. Outcomes of basic versus advanced life support for out-of-hospital medical emergencies. Ann Intern Med 2016;165:69-70.

9. Cournoyer A, Notebaert É, Iseppon M, Cossette S, LondeiLeduc L, Lamarche Y, et al. Prehospital advanced cardiac life support for out-of-hospital cardiac arrest: a cohort study. Acad Emerg Med 2017;24:1100-9.

10. Hagihara A, Hasegawa M, Abe T, Nagata T, Nabeshima Y. Physician presence in an ambulance car is associated with increased survival in out-of-hospital cardiac arrest: a prospective cohort analysis. PLoS One 2014;9:e84424.

11. Hamilton A, Steinmetz J, Wissenberg M, Torp-Pedersen C, Lippert FK, Hove L, et al. Association between prehospital physician involvement and survival after out-of-hospital cardiac arrest: a Danish nationwide observational study. Resuscitation 2016;108:95-101.

12. Böttiger BW, Bernhard M, Knapp J, Nagele P. Influence of EMS-physician presence on survival after out-of-hospital cardiopulmonary resuscitation: systematic review and meta-analysis. Crit Care 2016;20:4.

13. Cummins RO, Chamberlain DA, Abramson NS, Allen M, Baskett PJ, Becker L, et al. Recommended guidelines for uniform reporting of data from out-of-hospital cardiac arrest: the Utstein Style. A statement for health professionals from a task force of the American Heart Association, the European Resuscitation Council, the Heart and Stroke Foundation of Canada, and the Australian Resuscitation Council. Circula- 
tion 1991;84:960-75.

14. Rittenberger JC, Raina K, Holm MB, Kim YJ, Callaway CW. Association between Cerebral Performance Category, Modified Rankin Scale, and discharge disposition after cardiac arrest. Resuscitation 2011;82:1036-40.

15. Rosell-Ortiz F, Escalada-Roig X, Fernández Del Valle P, Sánchez-Santos L, Navalpotro-Pascual JM, Echarri-Sucunza A, et al. Out-of-hospital cardiac arrest (OHCA) attended by mobile emergency teams with a physician on board. Results of the Spanish OHCA Registry (OSHCAR). Resuscitation 2017;113:90-5.

16. Dyson K, Bray JE, Smith K, Bernard S, Straney L, Finn J. Paramedic exposure to out-of-hospital cardiac arrest resuscitation is associated with patient survival. Circ Cardiovasc Qual Outcomes 2016;9:154-60.

17. Gold LS, Eisenberg MS. The effect of paramedic experience on survival from cardiac arrest. Prehosp Emerg Care 2009;13:341-4.

18. Ohshige K, Shimazaki S, Hirasawa H, Nakamura M, Kin H, Fujii C, et al. Evaluation of out-of-hospital cardiopulmonary resuscitation with resuscitative drugs: a prospective comparative study in Japan. Resuscitation 2005;66:53-61.

19. McCarney R, Warner J, Iliffe S, van Haselen R, Griffin M, Fisher P. The Hawthorne effect: a randomised, controlled trial. BMC Med Res Methodol 2007;7:30.
20. Kocher KE, Sklar DP, Mehrotra A, Tayal VS, Gausche-Hill M, Myles Riner R; 2010 Academic Emergency Medicine Consensus Conference Beyond Regionalization: Intergrated Networks of Emergency Care. Categorization, designation, and regionalization of emergency care: definitions, a conceptual framework, and future challenges. Acad Emerg Med 2010;17:1306-11.

21. Drennan IR, Verbeek PR. The role of EMS in regionalized systems of care. CJEM 2015;17:468-74.

22. Cone DC, Brooke Lerner E, Band RA, Renjilian C, Bobrow BJ, Crawford Mechem C, et al. Prehospital care and new models of regionalization. Acad Emerg Med 2010;17:1337-45.

23. Martinell L, Nielsen N, Herlitz J, Karlsson T, Horn J, Wise MP, et al. Early predictors of poor outcome after out-of-hospital cardiac arrest. Crit Care 2017;21:96.

24. Kjaergaard J, Nielsen N, Winther-Jensen M, Wanscher M, Pellis T, Kuiper M, et al. Impact of time to return of spontaneous circulation on neuroprotective effect of targeted temperature management at 33 or 36 degrees in comatose survivors of out-of hospital cardiac arrest. Resuscitation 2015;96:310-6.

25. Salcido DD, Sundermann ML, Koller AC, Menegazzi JJ. Incidence and outcomes of rearrest following out-of-hospital cardiac arrest. Resuscitation 2015;86:19-24. 